\title{
The spectrum and outcome of surgical sepsis in Pietermaritzburg, South Africa
}

\author{
S Green, ${ }^{1}$ BSc Hons, MSc, MB BCh, DA (SA); V Y Kong, ${ }^{1}$ MB ChB, MSc, PhD, MRCS; D L Clarke, ${ }^{1,2}$ MMedSci, MBA, MPhil, PhD, FCS (SA); \\ B Sartorius, ${ }^{3}$ BSc, BSc Hons, MSc, PhD; J Odendaal, ${ }^{1}$ BSc (Med Sci) Hons; J L Bruce, ${ }^{1}$ FCS (SA); G L Laing, ${ }^{1}$ FCS (SA), PhD; \\ P Brysiewicz, ${ }^{3}$ BSocSc, BA, MCur, PhD; W Bekker, ${ }^{1}$ FCS (SA); E Harknett, ${ }^{1}$ BMedSci, BMBS, DA (SA) \begin{abstract}
School of Medicine, University of KwaZulu-Natal, Durban, South Africa
${ }^{2}$ Department of Surgery, Faculty of Health Sciences, University of the Witwatersrand, Johannesburg, South Africa

${ }^{3}$ School of Nursing and Public Health, College of Health Sciences, Howard College Campus, University of KwaZulu-Natal, Durban, South Africa
\end{abstract} \\ ${ }^{1}$ Department of Surgery, Pietermaritzburg Hospital Complex and School of Clinical Medicine, College of Health Sciences, Nelson R Mandela
}

Corresponding author: D L Clarke (damianclar@gmail.com)

\begin{abstract}
Background. Sepsis is a leading cause of morbidity and mortality worldwide, and the incidence appears to be increasing. In the resourcelimited environment in low- and middle-income countries, the management of surgical sepsis (SS) continues to represent a significant portion of the workload for most general surgeons.

Objective. To describe the spectrum of SS seen at a busy emergency department, and categorise the outcomes.

Methods. The Pietermaritzburg Metropolitan Trauma Service (PMTS) and Pietermaritzburg Metropolitan Surgical Service (PMSS) in KwaZulu-Natal Province, South Africa (SA), maintain a prospective electronic registry. All patients with features of sepsis among emergency general surgical patients $>15$ years of age admitted to the PMSS over the period January 2012 - January 2015 were identified. From this cohort, all patients with sepsis that required surgical source control or who had a documented surgical source of sepsis (i.e. had SS) were selected for analysis.

Results. Of a total of 6020 adult surgical patients on the database, a cohort of 1240 acute surgical patients with features of sepsis were identified, and 675 with SS were then analysed further. Of the 675 patients, $49.2 \%$ were male, and the mean age was 46 years (standard deviation (SD) 19); $47.0 \%$ presented to the PMSS directly from within the metropolitan area, while the remaining $53.0 \%$ were referred from hospitals outside the area. Physiological parameters (mean values) on presentation were as follows: systolic blood pressure $123 \mathrm{mmHg}$ (standard deviation (SD) 23), respiratory rate 22 breaths/min (SD 5.2), heart rate $107 \mathrm{bpm}(\mathrm{SD} 19)$, temperature $37^{\circ} \mathrm{C}(\mathrm{SD} 2)$ and white cell count $20 \times 10^{9} / \mathrm{L}$ (SD 8). Of the patients, $21.6 \%$ were known to be HIV-positive, $13.5 \%$ (91/675) were negative and $64.9 \%$ were of unknown status; $57.6 \%$ had intra-abdominal sepsis, $26.1 \%$ diabetes-related limb sepsis and the remaining $16.3 \%$ soft-tissue infections; $17.5 \%$ required intensive care unit admission, with a mean length of stay of 4 days (SD 4 ), and $30.7 \%$ developed complications. In this last group ( $n=207$ ), a total of 313 morbidities were identified. The overall mortality rate was $12.7 \%$ (86/675). The mortality rate for intra-abdominal sepsis was $13.1 \%$, for diabetic foot sepsis $14.2 \%$ and for necrotising fasciitis $27.3 \%$.

Conclusions. The spectrum of SS in SA is different to that seen in the developed world. Intra-abdominal sepsis is the most common SS and is overwhelmingly caused by acute appendicitis. Diabetic foot infection is a major cause of SS, reflecting the increasing burden of noncommunicable chronic diseases in SA.
\end{abstract}

S Afr Med J 2017;107(2):134-136. DOI:10.7196/SAMJ.2017.v107i2.11339

Sepsis is a leading cause of morbidity and mortality worldwide, and the incidence appears to be increasing. ${ }^{[1-4]}$ Surgical conditions are responsible for up to one-third of the overall disease burden of sepsis. The annual cost of hospital care of sepsis is estimated to be over USD14 billion in the USA alone. Surgical sepsis (SS) is a broad term covering a spectrum of conditions in which the patient has a septic process that requires surgical source control. In addition to operative management, these patients require aggressive resuscitation and organ support. ${ }^{[5-11]}$ In the resource-limited environment in low- and middle-income countries (LMICs), the management of SS continues to represent a significant portion of the workload for most general surgeons.

\section{Objective}

To review the spectrum of SS disease and outcome among patients who presented to a major tertiary surgical service in South Africa (SA).

\section{Methods}

This retrospective study was undertaken at Grey's Hospital in Pietermaritzburg, the capital of KwaZulu-Natal Province, SA. The Pietermaritzburg Metropolitan Surgical Service (PMSS) covers the entire western part of the province, with a total catchment population of over 3 million, most of whom are black Africans.

The electronic clinical registry ${ }^{[12]}$ at the PMSS was retrospectively reviewed from January 2012 to January 2015. The electronic registry is prospectively maintained in 'real time', where patients' clinical information is entered directly into an electronic database. On review of the prospectively maintained database, all emergency general surgical patients aged $>15$ years presenting to the emergency room who fulfilled the standard Surviving Sepsis Campaign (SSC) criteria $^{[1]}$ for systemic inflammatory response syndrome (SIRS), sepsis, severe sepsis or septic shock from January 2012 to January 2015 were identified. The following criteria (two or more had to be present) were used to identify patients with sepsis: fever (temperature $>38.3^{\circ} \mathrm{C}$ ) 
or hypothermia (core temperature $<36^{\circ} \mathrm{C}$ ), heart rate $>90 \mathrm{bpm}$ or more than two standard deviations (SDs) above the normal value for age, tachypnoea, altered mental status, and hyperglycaemia (plasma glucose $>7.7 \mathrm{mmol} / \mathrm{L}$ ) in the absence of diabetes. Once this cohort had been identified, the registry was reviewed to identify all patients with sepsis that required surgical source control or who had a documented surgical source of sepsis (i.e. had SS). Those with incomplete records or without subsequent surgical confirmation of the source of sepsis were excluded. Data reviewed from the registry included basic demographic information, admission physiological parameters, diagnosis, requirement for intensive care unit (ICU) admission, length of hospital stay and mortality. Morbidities were classified according to organ system, e.g. hospital-acquired pneumonia was classified as a respiratory complication. The surgical pathologies were classified into the following categories: intra-abdominal sepsis, limb sepsis and soft-tissue sepsis.

\section{Statistical analysis}

Data were processed and analysed using Stata version 13.0 (StataCorp, USA). Continuous variables were summarised using means and SDs. If there was evidence of skewing or asymmetrical outliers, medians and interquartile ranges were presented instead.

\section{Ethics approval}

Ethics approval for this study was formally granted by the Biomedical Research Ethics Committee of the University of KwaZulu-Natal (ref. no. BCA221/13) and the Knowledge and Epidemiology Unit of the Department of Health (no reference number).

Table 1. The spectrum of SS according to anatomical region $(N=675)$

\begin{tabular}{ll}
\hline & $\boldsymbol{n}(\%)$ \\
\hline Abdominal sepsis & $389 / 675(57.6)$ \\
Appendicitis & $156 / 389(40.1)$ \\
Perforated peptic ulcer & $60 / 389(15.4)$ \\
Biliary sepsis & $47 / 389(12.1)$ \\
Intra-abdominal abscess & $25 / 389(6.4)$ \\
Tuberculosis of the abdomen & $21 / 389(5.3)$ \\
Perforated viscus (non-peptic ulcers) & $31 / 389(7.9)$ \\
Pelvic inflammatory disease & $15 / 389(3.8)$ \\
Complicated bowel ischaemia & $14 / 389(3.5)$ \\
Diverticulitis & $5 / 389(1.2)$ \\
Anastomotic leak & $5 / 389(1.2)$ \\
Infective colitis & $4 / 389(1.0)$ \\
Peritoneal dialysis catheter sepsis & $4 / 389(1.0)$ \\
Primary peritonitis & $2 / 389(0.5)$ \\
Diabetic foot sepsis & $176 / 675(26.1)$ \\
Soft-tissue sepsis & $110 / 675(16.3)$ \\
Necrotising fasciitis & $33 / 110(30.0)$ \\
Soft-tissue abscesses & $77 / 110(70.0)$ \\
Head/neck & $24 / 77(31.2)$ \\
Perianal & $15 / 77(19.5)$ \\
Limbs & $11 / 77(14.3)$ \\
Trunk & $11 / 77(14.3)$ \\
Other & $16 / 77(20.8)$ \\
\hline
\end{tabular}

\section{Results}

\section{Demographics}

Of a total of 6020 adult surgical patients on the database, we identified 1240 acute surgical patients with SIRS. Of these, 675 patients with sepsis that required surgical source control or who had a documented surgical source of sepsis (i.e. had SS) were analysed further; $49.2 \%(332 / 675)$ were male, the mean age was 46 years (SD 19), and $47.0 \%(317 / 675)$ presented to the PMSS directly from within the metropolitan area, while the remaining 53.0\% (358/675) were referred from other hospitals outside the area.

\section{Clinical presentation}

Physiological parameters (mean values) on presentation were as follows: systolic blood pressure $123 \mathrm{mmHg}$ (SD 23), respiratory rate 22 breaths/min (SD 5.2), heart rate $107 \mathrm{bpm}$ (SD 19), temperature $37^{\circ} \mathrm{C}$ (SD 2), and white cell count $20 \times 10^{\circ} / \mathrm{L}$ (SD 8). Of the patients, $21.6 \%$ were known to be HIV-positive, $13.5 \%$ (91/675) were negative and $64.9 \%$ were of unknown status.

\section{Surgical disease spectrum}

Of the 675 patients, $57.6 \%(n=389)$ had intra-abdominal sepsis, $26.1 \%(n=176)$ had diabetes-related limb sepsis and the remaining $16.3 \%(n=110)$ had soft-tissue infections. Table 1 summarises the spectrum of surgical pathologies in each category. A total of 585 operative procedures were performed for source control. These are summarised in Table 2.

\section{Outcome}

Of all the patients, $17.5 \%(118 / 675)$ required ICU admission, with a mean length of stay of 4 days (SD 4), and 30.7\% (207/675) developed

Table 2. Procedures to obtain source control $(N=585)$

\begin{tabular}{ll}
\hline Procedures & $\boldsymbol{n}(\%)$ \\
\hline Laparotomy & $281(48.0)$ \\
Amputation & $148(25.3)$ \\
Incision and drainage & $55(9.4)$ \\
Debridement & $39(6.7)$ \\
Appendicectomy & $18(3.1)$ \\
Radiological procedure & $15(2.6)$ \\
Endoscopic retrograde & $13(2.2)$ \\
cholangiopancreatography & \\
Laparoscopic cholecystectomy & $8(1.4)$ \\
Open cholecystectomy & $8(1.4)$
\end{tabular}

Table 3. Organ system-related complications $(N=313)$

\begin{tabular}{ll}
\hline Complications (organ system) & $\boldsymbol{n}(\%)$ \\
\hline Neurological & $74(23.6)$ \\
Respiratory & $73(23.3)$ \\
Wound & $70(22.3)$ \\
Renal & $47(15.1)$ \\
Gastrointestinal & $30(9.5)$ \\
Cardiac & $17(5.4)$ \\
Urinary & $2(0.6)$
\end{tabular}


Table 4. Mortality according to site of sepsis

\begin{tabular}{llll}
\hline & \multicolumn{2}{c}{ Outcome } & \\
\cline { 2 - 3 } Site of sepsis & $\begin{array}{l}\text { Died, } \\
\boldsymbol{n}(\%)\end{array}$ & $\begin{array}{l}\text { Survived, } \\
\boldsymbol{n}(\%)\end{array}$ & Total, $\boldsymbol{N}$ \\
\hline Intra-abdominal & $51(13.1)$ & $338(86.9)$ & 389 \\
Diabetic foot sepsis & $25(14.2)$ & $151(85.8)$ & 176 \\
Soft-tissue sepsis & & & \\
$\quad$ Abscess & $1(1.6)$ & $60(98.4)$ & 61 \\
$\quad$ Necrotising fasciitis & $9(27.3)$ & $24(72.7)$ & 33 \\
$\quad-$ & $16(100)$ & 16 \\
Other & - & $589(87.3)$ & 675
\end{tabular}

complications during the course of their illness. A total of 313 morbidities were identified in these patients (Table 3 ). The overall mortality rate was $12.7 \%(86 / 675)$. The mortality rate for intra-abdominal sepsis was $13.1 \%$, for diabetic foot sepsis $14.2 \%$ and for necrotising fasciitis $27.3 \%$. Table 4 summarises mortality according to type of sepsis.

\section{Discussion}

Sepsis remains a leading cause of death and a significant health problem worldwide.$^{[1-5]}$ Despite the considerable amount of resources invested in managing and researching sepsis, the incidence continues to increase with little change in overall mortality. Most of the current management strategies originated from literature in the developed world (high-income countries, HICs), and literature focusing specifically on the spectrum of disease in LMICs is limited. ${ }^{[1-5]}$

Our study highlighted the fact that several aspects of SS in SA differ from the experience in HICs. ${ }^{[12-15]}$ The patient cohort is generally much younger than in HICs, as mean life expectancy is lower in SA. The most common SS is intra-abdominal sepsis, which is mainly secondary to acute appendicitis, followed by complicated peptic ulcer disease. In HICs, colonic perforation secondary to diverticular disease or colonic malignancies are generally the main sources of intra-abdominal SS. Although there is evidence to suggest that the incidence of diverticular disease in Africa is rising, it remains an uncommon cause of sepsis in our environment. ${ }^{[16]}$ The severity of acute appendicitis in SA has been well described in the literature, and appendicitis in SA carries significantly higher morbidity and mortality than in the developed world, primarily as a result of delayed presentation and poor access to healthcare. ${ }^{[17-19]}$ Patients generally present with more advanced disease than in HICs. Similarly, complicated peptic ulcer disease is rarely seen in HICs, where there is ready access to drug therapy and endoscopy services.

Non-communicable diseases (NCDs) are an increasing contributor to the burden of disease in SA. This was reflected in our study by the fact that over $25 \%$ of the surgical workload due to sepsis was for diabetic limb sepsis. A recent review of the burden of diabetes mellitus in KwaZulu-Natal showed that the number of patients initiated on treatment was increasing. ${ }^{[20]}$ The authors also showed a direct correlation between defaulting and the development of diabetic foot sepsis, and that diabetics are more likely than nondiabetics to require lower limb amputations (LLAs). In SA, diabetes is responsible for two-thirds of all LLAs. Poverty, poor sanitation, inadequate footwear and poor glycaemic control all contribute to this situation.

The overall mortality rate in our cohort was high. This is in keeping with studies from HICs, which report mortality rates ranging from $18 \%$ to $34 \%$. The mortality rate for intra-abdominal sepsis was similar to that for diabetic foot sepsis, once again emphasising the growing problem of NCDs in our environment. The mortality rate for soft-tissue sepsis varies dramatically between different types of softtissue infections. Subcutaneous abscesses have a negligible mortality rate, but once the infection involves the fascial planes the mortality rate increases dramatically. Advanced necrotising fasciitis reflects inadequate early recognition and referral by primary healthcare services.

\section{Conclusions}

The spectrum of SS presenting to an acute surgical service in SA is different to that seen in HICs. Intra-abdominal sepsis is the most common SS and is overwhelmingly caused by severe acute appendicitis and complicated peptic ulcer disease. Diabetic foot infection is a major cause of SS, reflecting the growing burden of NCDs in SA.

1. Dellinger RP, Levy MM, Rhodes A, et al. Surviving Sepsis Campaign: International guidelines for management of severe sepsis and septic shock. Crit Care Med 2013;41(2):580-637. http://dx.doi. org/10.1097/CCM.0b013e31827e83af

2. Moore LJ, Moore FA, Todd SR, Jones SL, Turner KL, Bass BL. Sepsis in general surgery: The 2005 - 2007 national surgical quality improvement program perspective. Arch Surg 2010;145(7):695-700. http:// dx.doi.org/10.1001/archsurg.2010.107

3. Moore LJ, Moore FA, Jones SL, Xu J, Bass BL. Sepsis in general surgery: A deadly complication. Am J Surg 2009;198(6):868-874. http://dx.doi.org/10.1016/j.amjsurg.2009.05.025

4. Hwang SY, Shin TG, Jo IJ, et al. Association between hemodynamic presentation and outcome in sepsis patients. Shock 2014;42(3):205-210. http://dx.doi.org/10.1097/SHK.0000000000000205

5. Villar J, Clement JP, Stotts J, et al. Many emergency department patients with severe sepsis and septic shock do not meet diagnostic criteria within 3 hours of arrival. Ann Emerg Med 2014;64(1):48-54. shock do not meet diagnostic criteria within 3 hours
http://dx.doi.org/10.1016/j.annemergmed.2014.02.023

6. MacQueen IT, Dawes AJ, Hadnott T, et al. Use of a hospital-wide screening program for early detection 6. MacQueen IT, Dawes AJ, Hadnott T, et al. Use of a hospital-wide screen
of sepsis in general surgery patients. Am Surg 2015;81(10):1074-1079.

of sepsis in general surgery patients. Am Surg 2015;81(10):1074-1079.
7. Glickman SW, Cairns CB, Otero RM, et al. Disease progression in hemodynamically stable patients Glickman SW, Cairns CB, Otero RM, et al. Disease progression in hemodynamically stable patients
presenting to the emergency department with sepsis. Acad Emerg Med 2010;17(4):383-390. http:// dx.doi.org/10.1111/j.1553-2712.2010.00664.x

8. Peake SL, Bailey M, Bellomo R, et al. Australasian resuscitation of sepsis evaluation (ARISE): A multi-centre, prospective, inception cohort study. Resuscitation 2009;80(7):811-818. http://dx.doi. org/10.1016/.j.resuscitation.2009.03.008.

9. Clarke DL, Chipps JA, Sartorius B, Bruce J, Laing GL, Brysiewicz P. Mortality rates increase dramatically below a systolic blood pressure of $105 \mathrm{~mm} \mathrm{Hg}$ in septic surgical patients. Am J Surg 2016;212(5):941-945. http://dx.doi.org/10.1016/j.amjsurg.2016.01.042

10. Scriba MF, Laing GL, Bruce JL, Sartorius B, Clarke DL. The role of planned and on-demand relaparotomy in the developing world. World J Surg 2016;40(7):1558-1564. http://dx.doi.org/10.1007/ s00268-015-3379-8

11. Scriba MF, Laing GL, Bruce JL, Clarke DL. Repeat laparotomy in a developing world surgical service. Am J Surg 2015;210(4):755-758. http://dx.doi.org/10.1016/.jamjsurg.2015.03.024

12. Laing GL, Bruce JL, Skinner DL, et al. Development, implementation, and evaluation of a hybrid . Laing GL, Bruce JL, Skinner DL, et al. Development, implementation, and evaluation of a hybrid
electronic medical record system specifically designed for a developing world surgical service. World J Surg 2014;38(6):1388-1397. http://dx.doi.org/10.1007/s00268-013-2438-2

13. Mamon AA, Siddqui FG, Abro AH, et al. An audit of secondary peritonitis at a tertiary care university hospital of Sindh, Pakistan. World J Emerg Surg 2012;7:6. http://dx.doi.org/10.1186/1749-7922-7-6

14. Burrow E, Anderson ID, Varley S, et al. Current UK practice in emergency laparotomy. Ann R Coll Surg Engl 2013;95(8):599-603. http://dx.doi.org/10.1308/003588413X13629960048433

15. Ariyaratnam R, Palmqvist CL, Hider P, et al. Toward a standard approach to measurement and reporting of perioperative mortality rate as a global indicator for surgery. Surgery 2015;158(1):17-26. http://dx.doi.org/10.1016/j.surg.2015.03.024

6. Matrana MR, Margolin DA. Epidemiology and pathophysiology of diverticular disease. Clin Colon Rectal Surg 2009;22(3):141-146. http://dx.doi.org/10.1055/s-0029-1236157

7. Kong VY, Sartorius B, Clarke DL. Acute appendicitis in the developing world is a morbid disease. Ann R Coll Surg Engl 2015;97(5):390-395. http://dx.doi.org/10.1308/003588415X14181254790608

18. Kong VY, van der Linde S, Handley JJ, Aldous C, Clarke DL. Quantifying the disparity in outcome between urban and rural patients with acute appendicitis in South Africa. S Afr Med J outcome between urban and rural patients with acute app

19. Kong VY, Bulajic B, Allorto NL, Handley JJ, Clarke DL. Acute appendicitis in a developing country. Kong VY, Bulajic B, Allorto NL, Handley JJ, Clarke DL. Acute appendicitis in a
World J Surg 2012;36(9):2068-2073. http://dx.doi.org/10.1007/s00268-012-1626-9

20. Pillay S, Lutge E, Aldous C. The burden of diabetes mellitus in KwaZulu-Natal's public sector: A 5-year perspective. S Afr Med J 2016;106(4):384-388. http://dx.doi.org/10.7196/SAMJ.2016.v106i4.9920 